\title{
Cognitive plasticity in adulthood and old age: Gauging the generality of cognitive intervention effects
}

\author{
Hannes Noack ${ }^{\mathrm{a}, *}$, Martin Lövdén ${ }^{\mathrm{a}, \mathrm{b}}$, Florian Schmiedek ${ }^{\mathrm{a}, \mathrm{c}}$ and Ulman Lindenberger ${ }^{\mathrm{a}}$ \\ ${ }^{a}$ Center for Lifespan Psychology, Max Planck Institute for Human Development, Berlin, Germany \\ ${ }^{\mathrm{b}}$ Department of Psychology, Lund University, Lund, Sweden \\ ${ }^{\mathrm{c}}$ Institute of Psychology, Humboldt-Universität Berlin, Berlin, Germany
}

\begin{abstract}
Interventions enabling aging individuals to fulfill their plastic potential promise to postpone, attenuate, or even reverse the adverse effects of senescent brain changes on cognitive abilities and everyday competence in old age. Based on an overview of the concept of plasticity in lifespan development, we selectively review evidence from cognitive intervention studies and conclude that most of them have failed to observe generalizable performance improvements, as documented by the small size and scope of positive transfer to untrained tasks. We further note that generally accepted criteria for defining transfer distance are lacking, rendering the relevant evidence difficult to interpret. Hence, we propose a taxonomy of transfer distance based on the structure of human intellectual abilities.
\end{abstract}

\section{Introduction}

It is common knowledge, and an annoying fact, that human musculature atrophies whenever we neglect physical exercise. However, we can be comforted by the knowledge that muscles will grow and regain strength when we engage in movement again. Though there is no direct translation of the mechanisms involved in this use-it-or-lose-it logic to the characteristics of our nervous system, both muscles and neurons share an inherent capacity for relatively long-lasting changes in response to experience - a capacity termed plasticity. For example, animal and human studies have revealed both negative effects of sensory deprivation (Buonomano and Merzenich, 1998; Draganski et al., 2006) and preserving, or even ameliorating, effects of environmental enrichment on the neuronal substrate of functioning (Briones et al., 2004, Kempermann et al., 1997; Milgram et al., 2006; van Praag et al., 2000).

*Corresponding author: Hannes Noack, Center for Lifespan Psychology, Max Planck Institute for Human Development, Lentzeallee 94, 14195 Berlin, Germany; E-mail: noack@mpib-berlin.mpg.de.
Thus, neuronal tissue reorganizes in response to sensory input, cognitive challenge, and the coordination of motor output.

In contrast to fluctuation and variability, plasticity typically requires substantial amounts of time and effort, as it needs to overcome the inherent inertia of biological cognitive systems (James, 1890; Lövdén in press; cf. Li et al., 2004; Lövdén et al., 2008). Differences between the notions of fluctuation, flexibility, and plasticity can be illustrated by an individual's performance on a memory test, which may vary for all three reasons. First, depending on daily variations in the level of fatigue, mood, and motivation, test scores will fluctuate across occasions due to factors that are transient and not directly related to the participant's memory ability (Lövdén et al., 2008). Second, the individual may switch to a more effective mnemonic strategy (e.g., from rehearsal to imaging) that both form part of her pre-existing behavioral repertoire. Fluctuation and flexibility both generate variations in performance level, but they both are different from plasticity, which requires changes in intrinsic capacity. In terms of the present example, memory test scores should undergo 
a robust increase that cannot be explained in terms of transient states or strategy shifts.

Cognitive plasticity can manifest itself in fluid cognitive abilities such as reasoning, working memory, and visuo-spatial reasoning. These abilities are known to decline in the course of normal aging (Rönnlund and Nilsson, 2006; Rönnlund et al., 2005; Schaie, 1996; Singer et al., 2003), probably reflecting senescent changes in gray matter volume (Raz et al., 2005), white-matter microstructure (e.g. Charlton et al., 2006; Sullivan and Pfefferbaum, 2006), concentration of neurotransmitters (e.g., dopamine; Bäckman et al., 2006), and cerebrovascular structure (Farkas and Luiten, 2001; Raz et al., 2005). Accordingly, the interplay between cognitive plasticity and cognitive aging is at the core of this review. More specifically, the central goal of this article is to shed light on the plastic potential of cognitive abilities in old age. To this end, we will review the available evidence on training-induced manifestations of cognitive plasticity in old age. We argue that the evidence generated by intervention studies is best understood from a lifespan perspective that distinguishes among the three interrelated concepts of maturation, senescence, and learning (e.g., Lindenberger, Li and Bäckman, 2006). Based on this general framework, we review studies from the lab of others and our own that investigate cognitive intervention effects in old age. In doing so, we will focus on the crucial question whether intervention effects generalize to cognitive abilities, or are restricted to the elements of skill that have practiced or trained (cf. Thorndike, 1906). In this context, we will propose a model for evaluating the degree of generality of training gains.

\section{Maturation, senescence, and learning}

Human cognition and the human brain maintain their ability to adapt to environmental influences from childhood through adolescence into young and even old adulthood (Baltes et al., 2006; Greenwood, 2007; Li et al., 2006; Pascual-Leone et al., 2005; Mercado, 2008; Lövdén, in press). Studies investigating effects of training and practice on cognitive tasks, such as episodic memory tasks (e.g. Baltes and Kliegl, 1992; Verhaegen and Marcoen, 1996; Derwinger et al., 2003; Brehmer et al., 2007; Brehmer et al., 2008), constitute a major source of evidence supporting this conclusion. These studies also qualify the persistence of cognitive plasticity throughout the lifespan by showing that the quality and the quantity of plasticity changes over the years. For example, Brehmer and colleagues (2007) showed that children aged nine to twelve years and older adults aged 65 to 78 gained comparably from instruction in a mnemomic technique in an episodic memory task (see Fig. 1). However, both groups differed remarkably in the way and in the amount they profited from different training components. While older adults benefited most from the strategy instruction, children gained more from subsequent repeated practice. Finally, younger children reached higher asymptotic performance levels than older adults, even though the two groups did not differ in performance at the beginning of the intervention. This example illustrates that plasticity can be expressed in different ways during different periods of the lifespan. Such differences in patterns of improvement provide helpful clues about age-graded differences in the mechanisms and the constituent components of cognition (Lindenberger et al., 2007; Shing et al., in press).

The general concepts of maturation, senescence, and learning facilitate the theory-guided discussion of agerelated differences and commonalities in behavior (Lindenberger et al., 2007). Both maturation and senescence extend throughout life. Though childhood is mostly characterized by maturation and old age is dominated by senescent processes, there is a large overlap in time and a long period of transition in between. For example, neurogenesis also occurs in the adult human dentate gyrus (Eriksson et al., 1998) while reductions in neurotransmitter concentration (Bäckman et al., 2006) and white matter integrity (Madden et al., 2004; Salat et al., 2004; Ota et al., 2006) may begin in early adulthood. Moreover, the course and nature of both processes for each individual strongly depend on the interaction between this person and her environment. Changes within the person that arise from this interaction can be referred to as learning. Thus, the sets of mechanisms subsumed under the headings of maturation, senescence, and learning mutually influence each other (Lindenberger et al., 2007), and never exist in isolation. This needs to be kept in mind when attempting to delineate their defining characteristics, as done below.

\subsection{Maturation}

Early childhood is characterized by the formation and specification of the brain, with some of the maturational changes in gray and white matter volume continuing well into adolescence (Lenroot and Giedd, 2006; Tsujimoto, 2008; Wozniak and Lim, 2006). Alterations 


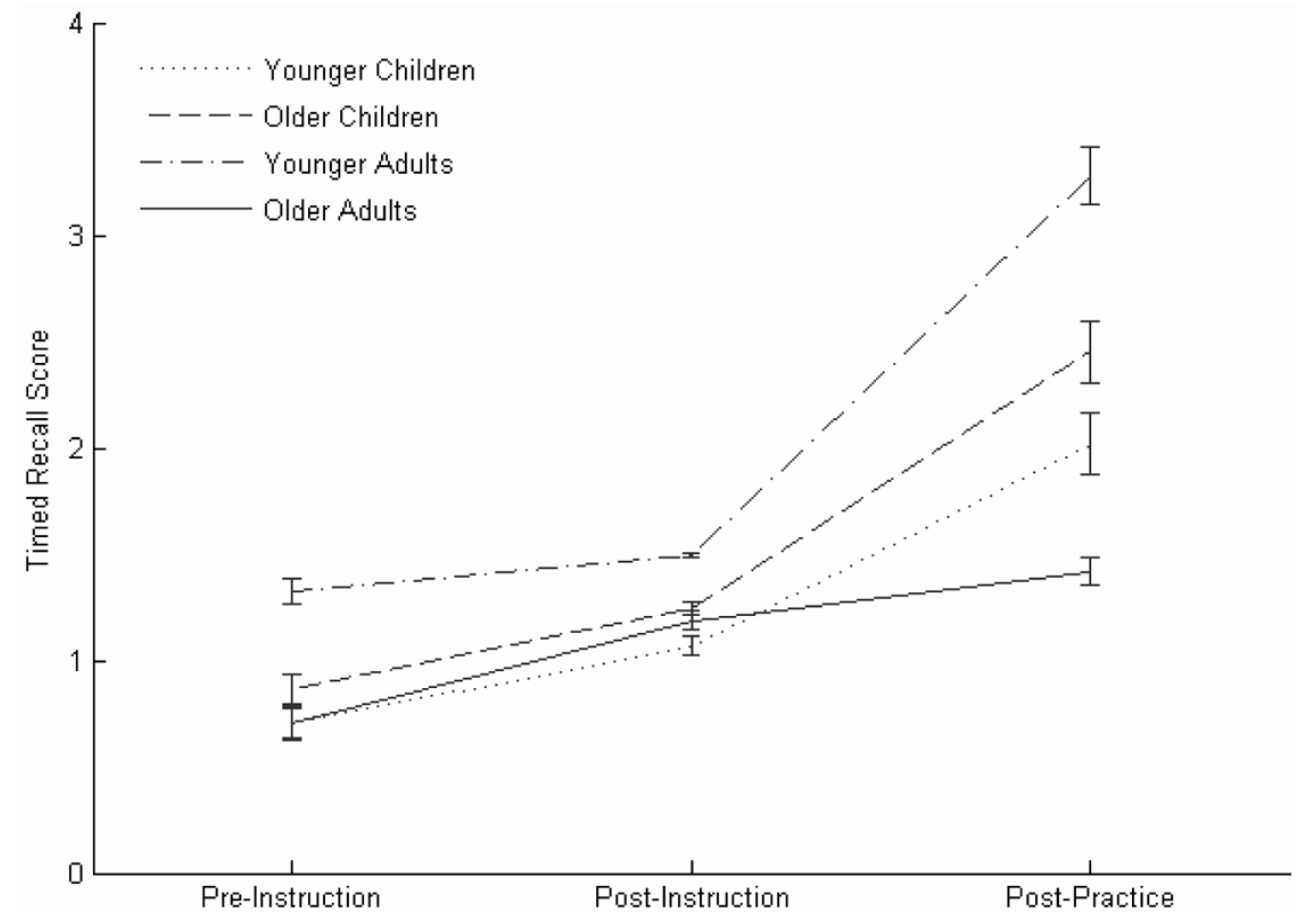

Fig. 1. Lifespan age differences in episodic memory plasticity. The timed recall scores for younger and older children and younger and older adults in relation to instruction and practice. Post-instruction scores of younger adults cannot be interpreted due to ceiling effects. Error bars represent standard errors. (adapted from Brehmer et al., 2007).

at the level of neuronal circuitry proceed in close temporal relationship with the emergence and refinement of cognitive capacities. For example, the development of receptive and productive language marches in steps with the maturation of Broca's and Wernicke's area (Huttenlocher, 2000). These changes result from interactions between genetic influences and learning. One exemplary description of the mechanisms involved in this interaction comes from the selective stabilization hypothesis (Changeux and Danchin, 1976). This hypothesis outlines two consecutive steps. First, guided by genetic influences, connections between main neuronal categories are established. This growth process leaves the young nervous system in a state of significant connective redundancy where the first synaptic connections that develop are in a labile state. The second step leads to specification of the neural network through selective stabilization. The driving force in this process is experience-related neural activation. Depending on the pattern of innervation, each synaptic connection can either turn into a stabile state or irreversibly regress. At the end of this period the neuronal circuitry stabilizes to a more or less "final wiring pattern" (Changeux and Danchin, 1976). We may conclude from these thoughts that the predominant task of early childhood develop- ment is to carry the brain from an unspecific and redundant state to a highly specified and differentiated one. This neural specialization has parallels in the cognitive system. For example, based on findings of higher correlations between intellectual abilities in children than in adolescents, early developmentalists have proposed a general intellectual ability that gradually differentiates into more distinct abilities (Lewin, 1946; Garrett, 1946).

These general conceptual remarks are consistent with the empirical results obtained by Brehmer and colleagues (2007) described above. Specifically, due to their high neuronal plastic capacity on the one hand and their limited strategic experience on the other hand, younger children might be gaining more from an experiential exploratory approach than from the use of abstract strategies. In other words, learning seems to be much more experience-driven and accidental than controlled and goal directed.

\subsection{Senescence}

Senescent changes increase in strength and number as individuals progress from adolescence into adulthood and old age (see e.g. Hedden and Gabrieli, 2004; 
Sowell et al., 2004 for reviews). For example, Raz and colleagues (2005) reported pronounced longitudinal decreases in gray matter volume, which may primarily reflect losses in connectivity (i.e., reduced dendritic and synaptic density), rather than reduced neuronal density (Hof and Morrison, 2004; Huttenlocher, 1979). In a similar vein, concentration of neurotransmitters, such as dopamine, and their receptors are reduced in aging (Bäckman et al., 2006). These marked changes in neuronal connectivity are accompanied by negative alterations in vascularization (Farkas and Luiten, 2001) and white matter integrity (Bartzokis, 2004; O'Sullivan et al., 2001; Sullivan and Pfefferbaum, 2006). Hence, the major developmental challenge of older organisms is to attenuate, avoid, or reverse the adverse behavioral consequences of senescent brain changes through lossinduced development, or compensation (B äckman and Dixon, 1992; Baltes et al., 2006).

Results from longitudinal investigations of cognitive aging clearly indicate that compensation, if present, is at least not fully successful (Rönnlund et al., 2005; Schaie, 1996; Singer et al., 2003). Pronounced agerelated decline has been observed for all fluid, mechanic abilities, such as working memory and reasoning. In contrast to this trend, crystallized, pragmatic abilities, such as general knowledge, metacognitive knowledge, and verbal knowledge, remain comparably intact throughout old adulthood. It seems plausible that elderly adults may rely comparatively more on these intact abilities in order to overcome deficits in impaired functions. Specifically, older adults may often rely more on their strategic or heuristic knowledge that they have acquired in the course of their lives than on their decreased capacity for new learning (see also Lövdén, 2003).

In addition to these considerations, findings from behavioral (see Schäfer et al., 2006, for review) and functional imaging studies suggest that the range of situations that require cognitive control expands from early to late adulthood. For example, increased levels of activation in the prefrontal cortex during movement coordination have been taken to reflect an increased amount of cognitive monitoring (Heuninckx et al., 2005). Similarly, increased frontal cortical activation has been found in cognitive tasks (Grady, 2001; Cabeza et al., 2002; Cabeza et al., 2004; Gutchess et al., 2005; Davis et al., 2008). Such altered cortical activation patterns in aging have often been interpreted to reflect compensatory plasticity or decline-induced plastic changes (Greenwood, 2007; Lövdén, in press; Park and Reuter-Lorenz, 2009). These findings are consistent with our interpretation of the results reported by Brehmer and colleagues (2007). In contrast to children, the older participants in this study seemed to rely on their heuristic and strategic knowledge.

\subsection{Learning}

Human beings are characterized by their superior capacity to adapt their behavior to environmental demands. This process of experience-related change is called learning (Lindenberger, 2008). On the cortical level this change might be reflected in the change of representational maps, such as alterations in their cortical areal extent (e.g., Buonomano and Merzenich, 1998). Thus, learning and plasticity are closely related terms. In our understanding, however, plasticity denotes the capacity for change, whereas learning denotes the process of change.

As described in the two preceding paragraphs, the quality and quantity of cognitive and neuronal plasticity changes throughout the lifespan (Kolb et al., 1998). For instance, based on findings from deprivation and enrichment in animal studies, Greenough, Black, and Wallace (1987) distinguish two types of plasticity. During early childhood, the organism is faced with the need to incorporate basic information such as contrast, color, and orientation in the visual domain. Environmental input of this kind is ubiquitous to all members of a certain species and can therefore be expected from an evolutionary point of view. Indeed, infant organisms are prepared to process novel information through the mechanisms described by the selective stabilization hypothesis (Changeux and Dehaene, 1976). Hence, this kind of early plasticity can be termed experienceexpectant (Greenough et al., 1987). Without doubt, however, learning occurs beyond the age of 10 to 15 years, when synaptic density reaches its asymptote in most brain regions (see e.g. Tsujimoto, 2008). After main cognitive categories have been established during early development, organisms need to retain a certain amount of plasticity to dynamically adapt the associations between these categories according to individual experiences (Singer, 1995). This type of individualized malleability is warranted by mechanisms such as the establishment of new synaptic connections. Because the kind and extent of these changes strongly depend on the actual experience of a certain individual it was termed experience-dependent plasticity (Greenough et al., 1987). These considerations suggest that experience-related activations of the cortical circuitry are the major driving force of learning across the 
lifespan. In part, experience-expectant and experiencedependent plasticity may operate through similar mechanisms such as long-term potentiation and depression (see Cooke and Bliss, 2006; Hensch, 2004, 2005, for reviews), but their neuronal and behavioral outcomes may differ greatly (c.f. Knudsen, 1998).

Representational plasticity in the sense of strengthening of existing neuronal pathways might thus be only the first step in a cascade of cortical shaping related to learning experiences and may be followed by the consolidation of altered cortical representations. For example, Pascual-Leone and colleagues (1995) showed that neural representations of fingers can grow in size after finger movement practice. Early in practice, this effect was rather transient and dependent on the amount of preceding training. Later in practice (after five weeks), the baseline size of the cortical finger map was larger, while the practice effect became smaller. The authors interpreted these results as a reflection of initial changes governed by fast modulatory adaptation of existing pathways followed by a long-termed structural change in intracortical and subcortical networks (see also Karni et al., 1995). In accordance with this twostage model, recent evidence from neuroimaging studies has revealed that intensive practice can lead to alterations in density and volume of cortical and subcortical gray matter (Draganski et al., 2004; Draganski et al., 2006; May et al., 2007) in both younger and older adults (Boyke et al., 2008). Though the biological substrates of these changes are not well understood, these findings are in line with abundant animal evidence about adult plastic changes in brain structure, such as neurogenesis, synpatogenesis, and angiogenesis (see Churchill et al., 2002; Li, 2003; Kempermann, 2006, 2008, for reviews). In sum, principles of learning in the adult human brain differ from those found in the infant brain. Still, the adult brain retains an impressive capacity for experience-related change.

\section{Plasticity, training, and transfer}

Taking the last three paragraphs together, we conclude that the three concepts of lifespan development are mutually dependent. Learning takes place in interaction with the processes of maturation, and the course and the outcome of maturation itself is strongly dependent on learning. In addition, senescence and its expression in everyday behavior are determined by the lifetime history of learning and maturation. For example, alterations in cognitive and brain functioning in childhood and early adulthood may affect the age at which functional impairment threshold is reached in old age as well as directly influence the course of cognitive aging by altering the effectiveness of adaption to senescent changes (Hertzog et al., in press; Lövdén, in press; Lövdén et al., 2008; Stern, 2002).

As reviewed above, senescence leads to progressive deterioration in major cognitive abilities such as working memory, reasoning, and episodic memory. Whether this decline is inevitable or susceptible to environmental intervention has been a matter of empirical inquiry and conceptual debate for over thirty years (Baltes and Schaie, 1976; Horn and Donaldson, 1976). Specifically, research seeking to identify mechanisms, conditions, and limitations of cognitive and brain plasticity in old age needs to examine whether older adults (a) can reactivate knowledge and skills present earlier in life; (b) possess the capability to acquire new knowledge and skills (Baltes and Lindenberger, 1988); (c) possess sufficient cognitive plasticity to enhance their cognitive abilities through sustained training and deliberate practice. The answer to the last question has direct implications for intervention strategies aiming at ameliorating everyday competence in old age (Lindenberger, 2000). If cognitive interventions do not improve cognitive abilities, then training highly artificial tasks in the laboratory may have relatively little effects on cognitive competence in everyday life, except perhaps by improving cognitive self-efficacy beliefs (Dittmann-Kohli et al., 1991). In this case, interventions should focus directly on skills that are of immediate utility in the ecologies of elderly individuals. If, on the other hand, interventions can be shown to enhance cognitive abilities in a sustained manner, then the benefit for the aging individual may be rather general, and the tasks taxing that ability in the most efficient manner would be a recommendable tool for training from an applied perspective, regardless of how decontextualized and artificial it may look.

Therefore, the following review of training studies will concentrate on positive transfer of training, as it serves as the transmission belt connecting the laboratory settings of psychological investigations to the tasks and affordances of daily life. Our review is not intended to exhaustively cover the field of cognitive training research. Rather, we focus on recent studies and paradigms apt to shed light on the generality of performance improvements associated with cognitive interventions. In addition, our review of the literature is restricted to the behavioral level of analysis (for neural manifestations of transfer, see the recent study by Dahlin et al., 2008). 


\subsection{Strategy-based training}

In an extended trial, called PRO-ALT, which was a continuation project of the Penn State Adult Development and Enrichment Project (Baltes and Willis, 1982), Baltes, Dittman-Kohli, and Kliegl (1986) investigated how modifiable fluid intelligence in the elderly is in response to intervention and practice. Their sample included 204 older adults with a mean age of 72 years (range $=65-85$ years). The study was split into three major parts: a pretest, a cognitive training phase, and three posttests. The participants were randomly assigned to either a trainer-guided practice group where strategy instruction was given, or a retest-practice control group. The training period consisted of two times five 1-hour sessions dealing either with a figural relations task or an induction task. Pre- and posttests consisted of some tasks closely related but not identical to the trained material (such as Raven's Advanced Progressive Matrices and Culture Fair Test for figural relations and Induction Standard Tests for induction) and some that did not tap the trained abilities directly (e.g. perceptual speed tasks, such as Identical Pictures or tests of crystallized intelligence such as a vocabulary test). Therefore the study was nicely designed to uncover potential near and far transfer-effects. Results revealed a medium to large and persistent effect size in near transfer tasks $(d=0.5, d=0.66)$ but there was only limited evidence for far transfer effects (see also Denney and Heidrich, 1990). Similar results were obtained in another study examining the effects of selfguided in contrast to tutor-guided training (Baltes et al., 1989; Derwinger et al., 2003). Self-guided practice led to similar performance improvements as instructed training, but as in the previous study (Baltes et al., 1986) training produced "a narrow band of withinability transfer".

In a related vein, Kliegl, Smith, and Baltes (1986, $1989,1990)$ investigated the effects of strategy instruction on episodic memory performance. Training studies employed mnemonic techniques that helped participants to encode, organize, and retrieve items from lists, such as the method of loci (Kliegl et al., 1986, 1989, 1990), the pegword mnemonic (Wood and Pratt, 1987), or the face-name mnemonic (Yesavage, 1983a; 1983b: Yesavage et al., 1983). Typically, the cognitive strategies were instructed first and then followed by a period of more or less extended practice. In a meta-analysis, Verhaeghen, Marcoen, \& Goosens (1992) evaluated the training gains achieved in 31 cognitive training studies including a total of 1539 people at a mean age of 69.1 years. They showed that the mnemonic treatment $(d=$ $0.73)$ was effective compared to placebo $(d=0.37)$ and control treatment $(d=0.38)$. Gains were largest when the participants were young, when training sessions were short, when pretraining was provided, and when the training sessions were held in groups. However, those studies that investigated transfer showed that the effect of the mnemonic was highly specific; that is, effects were generally not reliable whenever the trained strategy could not be used to memorize the materials. This result of limited generalization of training-related improvements in memory skill has been replicated several times (Cavallini et al., 2003). Stigsdotter Neely and Bäckman (1993a, 1993b, 1995), for example, combined strategy instructions with interventions aiming at improving attentional focusing and relaxation. This series of investigations revealed that composite memory intervention programs had a greater impact on participants' performance (Stigsdotter Neely and B äckman, 1993a; 1993b), but modest signs of transfer were restricted to one study (Stigsdotter Neely and Bäckman, 1995). The latter result must be interpreted with caution because the transfer task was structurally equivalent to the trained one and only differed in content (remembering objects instead of concrete words). Several other multifactorial training studies have also failed to show transfer effects (Caprio-Prevette and Fry, 1996; Mohs et al, 1998).

More recent studies have tried to directly assess the impact of cognitive training on everyday functioning and quality of life. In the extensive $\mathrm{ACTIVE}^{1}$ study $(\mathrm{N}=2832$; age range $=65-94$ years $)$, Ball and colleagues (2002) instructed their participants in strategy use for verbal episodic memory, reasoning, and speed of processing. After strategy instruction every group engaged in exercises for practice. The study also comprised a no-contact control group. Training was given to the three experimental groups in 10 group sessions and in four booster sessions 11 months later. The results for the memory and the reasoning group showed persistent reliable small to medium net effect sizes (memory: $d=0.26$; reasoning: $d=0.48$ ) in the immediate posttest of the trained task. The training effect in the perceptual speed group, however, was strong $(d=-1.46)$. Finally, transfer to a non-trained domain was absent. The same was true for a second testing battery that aimed at assessing everyday life processing.

\footnotetext{
${ }^{1}$ ACTIVE stands for Advanced Cognitive Training for Independent and Vital Elderly.
} 
This result, however, was attributed to the absence of marked decline in everyday functioning for the control group. In sum, the authors of this large-scale, randomized trial replicated previous findings of task-specific improvement, and did not find evidence for transfer.

In a five-year follow-up study, Willis and colleagues (2006) showed a weak gain of the reasoning group on the self-reported measures of daily functioning. Yet, all the other groups did not gain compared to the control groups. Special emphasis was put on perceptual speed training (see Ball et al., 2007 for a review) in a related series of studies. The training regime followed the logic of the useful-field-of-view (UFOV) approach introduced by Ball and colleagues (1988; see also Edwards, Vance et al., 2005; Edwards et al., 2006). Participants were confronted with a time-constrained visual identification or discrimination task in a single (targets were presented centrally on a screen) and a parallel (two targets were presented centrally and peripherally either pure or surrounded by distractors) condition. As training progressed display presentation times decreased and task complexity increased. Despite of the substantial relation between performance in the UFOV test and other psychometric measures assessing processing speed (digit-symbol substitution, pattern comparison, letter comparison; see Ball et al., 2007), evidence for transfer to these measures was meager. No training benefits were shown for any of the aforementioned tasks and other standard psychometric measures (e.g. Stroop and digit and spatial span; Edwards et al. 2002; Edwards et al., 2005). In a study by Vance and colleagues (2007), though, nearest transfer was shown to the Starry Night test (Rizzo and Robin, 1996), a measure of visuo-spatial attention. Finally, Edwards and colleagues (2002; Edwards, Wadley et al., 2005) obtained reliable transfer to the Timed Instrumental Activities of Daily Living (TIADL). This measure comprises the speed of processing in every day tasks such as looking up a telephone number from a list or reading the ingredients on a food can. Though these results are qualified by a comparison with an active control group in one study only (Edwards, Wadley et al., 2005), they point to the potential practical utility of the UFOV approach. This interpretation is further underlined by results showing improved driving competency after UFOV training (Roenker et al., 2003). Due to the absence of transfer to all assessed standard psychometric tests, however, these studies provide only little information for the theoretical discussion of transfer effects.

Following a somewhat similar logic, Caserta, Young, and Janelle (2007) investigated the effects of a perceptual-cognitive skills training. The concept of situational awareness was at the core of this intervention. The authors trained their participants to focus attention on task-relevant cues, to integrate these cues into the situational context, and to anticipate the outcomes. Five days of training were given in a tennis context where the trained participants received instruction and deliberate practice in situational awareness. Results showed that training led to a decrease in tennis specific reaction time, together with increased response and decision accuracy. These findings are contrasted with results coming from an active control-group that received the same amount of training in tennis footwork and technique. Moreover, a passive control-group was evaluated as well. The latter groups did not show significant increases in the dependent measures. Though the improvements in tennis performance were quite impressive, the transfer to other contexts was not shown and must be considered unlikely because the training imparted mostly tennis-specific strategic knowledge. Thus, trained participants might have increased their capacity to predict the game and therefore react faster and more accurately. Accordingly, no gains in standard measures of perceptual speed were observed.

\subsection{Process-based training}

More recently, the widespread absence of transfer effects as well as findings indicating low strategy use among older participants (Verhaeghen and Marcoen, 1996) have led to a shift in intervention design. Rather than introducing an explicit strategy to participants, more recent approaches have focused on practice-based interventions targeting more general processing capacities, such as working memory and cognitive control. The concept of cognitive control (e.g., Miller and Cohen, 2001) has been implemented in intervention studies mainly through two different skills: dual-tasking and task-switching. Recollection training as a third and related concept was introduced by Jennings, Webster, Kleykamp, and Dagenbach (2005).

Training of cognitive control. In an age-comparative study, Kramer, Larish, and Strayer (1995) examined trainability of dual-task performance. Two modes of dual-tasking were introduced to an intervention group and a contact-control group: (1) The aspect of executive control was emphasized in the experimental group by a variable priority (VP) regime, where the weighting of each single task was varied from block to block. (2) In the contact-control group the priority of the single tasks remained fixed (FP) throughout the whole ex- 
periment. The authors expected that a lower amount of executive control would be needed in this condition due to automatization. The procedure included three sessions of introductory testing and pretraining, three sessions of FP vs. VP training, and two more sessions of transfer assessment. The trained task consisted of a continuous monitoring task and an alphabetic arithmetic task. The transfer battery, on the other hand, consisted of a running-memory task and a scheduling task in both a single and a dual-task condition. It should be noted that these tasks closely resembled the general architecture of the trained task but used different material in the single tasks. Expected transfer effects would therefore result from a trained dual-task skill rather than strategy development or automatization on the single tasks. Results showed that the VP training led to higher improvements in the trained tasks than the FP training. This effect was stronger for the old than for the young and stronger for the dual-task condition than for the single task condition. Importantly, performance in the transfer tasks indicated that the participants had learned a dual-task skill during the three sessions of training. This was true, however, only for the participants trained in the VP training regime. The authors interpreted these results as an indication of an increased and generalized skill to coordinate and manage multiple tasks. Note, however, that the transfer task was not applied at pretest. It is therefore difficult to interpret the reported difference between the groups at posttest as training gains.

This limitation was remedied in a subsequent study by Bherer and colleagues (2005). In this study, the training tasks included auditory discrimination (high or low tone) and visual identification (letter B or C). Dual-task costs were estimated by subtracting the performance of the single task condition with that of the dual task condition. There were two transfer tasks. Nearest transfer was assessed by the "within-modality" task. In this case the participants again had to discriminate tones (smooth or rough) and identify digits (three or five). The "cross-modality" transfer task can be considered as a task tapping near transfer. In this case the auditory part of the dual-task was replaced by another visual discrimination task (pattern discrimination). The results of the intervention group were contrasted to the performance of a no-contact control group. A significant training effect was expressed by reduced dual-task costs for both the younger and the older trainees compared to the controls. The same was true for both of the transfer tasks. Note, however, that the mere execution of the single tasks may have led to improved stimulus-response mappings instead of task organizational skills. With this in mind, observed reduced dual-task costs can be attributed to automatization instead of an increased ability to coordinate multiple tasks. This effect cannot be ruled out since there was no active control group performing only the single tasks.

Partly motivated by these findings of training-related improvements in executive control, Karbach and Kray (in press) investigated transfer of these gains to new tasks. The sample consisted of three groups: 56 children (mean age $=9.2$; range $=8.1-10.1$ years), 56 younger adults (mean age $=22.4$; range $=18.0-26.3$ years), and 56 older adults (mean age $=68.7$; range $=$ 62-3-76.8 years). We review the results for the elderly only. The study was designed as a pretest-trainingposttest control-group design with only 4 training sessions. The criterion task was a task-switching task consisting of figural choice-reaction tasks. Participants had either to decide on the size (big or small) or on the nature (e.g. fruit or vegetable) of a presented picture. Members of the training group had to switch their focus on every other trial. The control group, however, worked on either of the two tasks for entire blocks of trials. The cognitive test battery that served as transfer tasks consisted of four different tests thought to tap different constructs such as inhibitory control (e.g. Color-Stroop task), verbal working-memory (e.g. reading span), visuospatial working-memory (e.g. navigation span), and reasoning or fluid intelligence (e.g. Raven's Standard Progressive Matrices). Results revealed training gains on structurally similar task-switching tasks $(d=0.12$ for single task control group vs. $d=0.95$ for the intervention group ${ }^{2}$ ) for the elderly. A similar pattern was found for all four far transfer tasks (net effect sizes were between 1.3 for Stroop and 0.3 for spatial workingmemory $\left.{ }^{3}\right)$. The far transfer to various domains of cognitive functioning is particularly remarkable, given that the intervention consisted of only four sessions.

Training of recollection. The differential effect of training on automatic (familiarity) and controlled (recollection) memory processes (Jacoby, 1991) was investigated by Jennings and colleagues (2005). Familiarity is assumed to be a fast and automatic process that is relatively unaffected by senescent changes in cognition. In contrast, recollection is more resource demanding, intentional, and strongly influenced by age.

\footnotetext{
${ }^{2}$ Effect sizes were estimated from a figure.

${ }^{3}$ Effect sizes were estimated from a figure.
} 
These assumptions led the authors to develop an intervention that specifically aimed at the controlled component of memory processing, tapping mechanisms such as working memory, interference control, and inhibition. In order to train recollection ability, trained participants $(\mathrm{N}=17$; mean age $=70$ years $)$ learned a list of words first. Then a second list of old and new words was presented. Whenever the participants identified an old word in the new list they had to respond with "yes". New words appeared twice in the second list in order to force the participants to recollect the old words instead of just relying on the impression of familiarity. The participants were asked to always respond with "no" to these words. During the training period the difficulty of the recollection task was adapted by an increasing lag between two new words in the second list. Jennings and colleagues also included a no-contact control group $(\mathrm{N}=12$; mean age $=65$ years $)$ and a contact control group $(\mathrm{N}=17$; mean age $=71$ years $)$, including participants that performed a simple recognition task. The training consisted of a total of six sessions spread over three weeks. The set of transfer tasks comprised tasks that were considered as near (e.g. n-back, self-ordered pointing, and source-monitoring) and those that were considered as far transfer (e.g., digit symbol substitution, reading span, and the California-Learning Test, CVLT-II). Training had a strong effect on the performance in the criterion task. Unfortunately, the performance of the two control groups in the criterion task was not reported so that the effect is hard to interpret. Results for the near-transfer tasks were rather heterogeneous. Significant group (training vs. transfer group) by time point (pretest vs. posttest) interactions were found for the 1-back and the 2-back tasks only. Especially in the 1-back task, this effect might have been due to the low baseline level of the training group. Though the authors found significant pretest to posttest increases for the self-ordered pointing task and the source discrimination task, these effects were not qualified by significant group by time interactions. Far transfer was completely absent.

Training of working memory. Another central constituent of cognitive functioning is working memory (Baddeley, 2007). Although there is ample data investigating episodic memory in the elderly, the trainability of this central ability in old age has rather been neglected. Recent research has looked on the effects of working memory training in young adults (Jaeggi et al., 2008; Olesen et al., 2004; Persson and Reuter-Lorenz, 2008) and children (Klingberg et al., 2005). All of these studies proved the effectiveness of the respective training regime on the criterion task. Moreover, some of the studies showed transfer of the training gains to measures of fluid intelligence (Jaeggi et al., 2008) or executive control (Klingberg et al., 2005). This approach therefore seems rather promising for the induction of broad transfer effects also in the elderly.

Dahlin, Stigsdotter Neely, Larsson, Bäckman, and Nyberg (2008) addressed transfer of training of updating operations in a recent fMRI study. A letter updating task served as the criterion task. A list of letters was presented serially to participants, who had to keep the last four letters they had seen in mind. The transfer task was a numerical n-back task (loads: 1, 2, 3). Participants saw a sequence of numbers and decided whether these corresponded to the one they had seen one, two, or three numbers before. Note that the structure of both tasks is similar because the central challenge is to update the content held in memory. As the participants practiced also with lists from other content domains (i.e., numbers, colors, and spatial locations) the only difference between the two tasks was due to load extent and response format. In addition to these two tasks, the Stroop test was assessed as a second transfer task. Computerized training was given for five weeks. Results showed transfer to the n-back task with a load of three for the younger, but no transfer effects for the older participants. Performance in the Stroop test was not affected by the intervention.

$\mathrm{Li}$ and colleagues (2008) investigated the effects of extended working memory training on working memory performance on near and far transfer tasks. The study comprised an intervention and a no-contact control group. Participants of the experimental group received a spatial 2-back task and a second similar but more complex task. ${ }^{4}$ The outcome measures were categorized as criterion (the trained tasks), near (a spatial 3-back and three numerical n-back tasks), and far (two complex memory span tasks, a spatial, and a numerical decision speed task) transfer. Participants practiced the criterion tasks for 45 days, with 15 minutes of practice per day. Results revealed significant net gains in the criterion tasks for both younger and older participants. Both groups gained more in the more complex condition than in the simple 2-back task. Significant near transfer was found on all measures except

\footnotetext{
${ }^{4}$ The design of the second task was equal to the 2-back task. Additional complexity was induced through the instructions. Participants had to shift the current position mentally by one step in clockwise direction. Every new appearing position had to be compared to the mentally shifted position of the target seen two trials ago.
} 
of the accuracy measure of the numerical 2-back task. Net-effect sizes for the older participants were medium $(d=0.3$ for accuracy in numerical 3-back) to large $\left(d=1.2\right.$ for RT in spatial 3-back). ${ }^{5}$ These effects were reduced but persisted until the second posttest taken three months after the end of the intervention. No reliable signs of far positive transfer were observed. On the contrary, the authors reported one significant interaction between group, age, and testing occasion, indicating that the trained older participants decreased in their performance on one of the complex span tasks. This absence of any far transfer stands in contrast to the findings of other studies described previously (Jaeggi et al., 2008; Persson and Reuter-Lorenz, 2008). On the other hand, the existence of positive transfer for n-back differs from the results reported by Dahlin et al. (2008), who studied a similar task (updating) but found no transfer for this age group at all. It appears from these comparisons that the effects of working memory training are strongly dependent on the materials and the procedural features of the training regime. The authors, therefore, suggest a fine-grained continuum of transfer tasks within the domain of working memory. This would offer the possibility to investigate the observed continuum of transfer in working memory trainings more systematically and to extract the central causal factors.

\subsection{Multifactorial approaches}

Mahncke and colleagues (2006; Mahncke, Connor et al., 2006) based their training approach on a multifactorial battery of tasks tapping basic sensory functions (identification, discrimination) and cognitive functions (short-term memory, text comprehension). In a randomized controlled trial (Mahncke et al. 2006), the authors assigned 182 participants (age range $=60-$ 87 ) to three groups (a training group, a contact control group, and a no-contact control group). In a total of 40 one-hour sessions the intervention group was provided with six tasks of adaptive difficulty. The contact control group watched and listened to DVD-based educational lectures for the same amount of time, while the nocontact control group did not receive any kind of intervention. Results indicated that the intervention group improved on all trained exercises. In a standardized test of global auditory memory (RBANS ${ }^{6}$ ), serving as a

\footnotetext{
${ }^{5}$ Effect sizes were estimated from a figure

${ }^{6}$ Only the six tests of auditory cognition (list learning, story memory, digit span forward, delayed free recall, and delayed story recall) within the RBANS were used as primary outcome measure.
}

transfer task, only the intervention group improved significantly $(d=0.25)$. Correcting for test-retest effects $(d=0.1)$ reduces the training-related gain to a weak effect of $d=0.14$. The authors suggested that ceiling effects in the RBANS measures might have corrupted the result. Rerunning the analysis on a subsample of the participants who performed below $85 \%$ on all subtests of the RBANS revealed a higher training-related effect size $(d=0.6)$ than in the total sample. Unfortunately, this result is difficult to evaluate further because the authors did neither report between-group differences nor the effect sizes for the control groups.

In a recent study, Basak, Boot, Voss, and Kramer (2008) evaluated the effects of playing strategy computer games on older adults cognitive performance. Earlier evidence from younger adults indicated that playing fast first-person shooter games had a beneficial effect on visual and attentional abilities (Green and Bavelier, 2006, 2007). Similarly, Gopher, Weil and Bareket (1994) demonstrated that flight performance of young Israeli Air Force cadets was dramatically and persistently improved through instructed computer game playing. The authors attributed this beneficial effect to improvements in attentional control skills. Rather than attentional and perceptual speed the computer game used by Basak and colleagues (Rise of Nations) demanded abilities such as complex problem solving, dual-tasking, working memory, and spatial orientation. Participants played this game with constant feedback for a total of 23.5 hours. Before and after the training they were provided with a battery of cognitive tests assessing either executive control (e.g. operation span, task-switching, n-back, Raven's Advanced Progressive Matrices) or visuospatial attention (e.g. functional field of view, attentional blink, enumeration, mental rotation). Performance of the training group was contrasted with those of a no-contact control group. Playing strategy games resulted in increased performance in four out of six cognitive tests tapping executive control (task-switching, n-back, visual short term memory, Raven's Advanced Progressive Matrices) and one tapping visuospatial, attentional abilities (Mental Rotation). Effects ranged from medium ( $d=$ $0.35)$ for the Raven to small $(d=0.22)$ for Mental Rotation.

For two reasons, the impressive transfer effects found by Basak et al. (2008) need to be interpreted with caution. First, the cognitive abilities tapped by the cognitive testing battery might have been trained directly during gaming practice. Especially task organization, parallel task monitoring, working memory, and orien- 
tation are likely to be part of the demands posed by the game. It is therefore difficult to tell whether the results reflect near or far transfer. Second, performance gains in the trained group may reflect a wealth of factors, as an active control group was not included in the design of the study. Possibly, motivational effects, social activation or familiarization with the testing environment (e.g. usage of a computer) might account for an unknown portion of the results.

\subsection{Social and physical activity}

One critical issue in aging research refers to the question of the influence of lifestyle on the course of senescence. Several studies have shown that an active lifestyle is related to decelerated cognitive decline in aging (e.g. Lövdén et al., 2005; Rogers et al., 1990; Schooler and Mulatu, 2001; for review, see Hertzog et al., in press). Analyzing longitudinal data from the Berlin Aging Study (BASE) with dynamical structural equation modeling, Lövdén and colleagues (2005) showed that an active lifestyle precedes and predicts changes in perceptual speed, but that perceptual speed did not precede and predict alteration in lifestyle. The authors emphasized that there is a lack in understanding of the causal mechanisms behind this protective effect. They suggested two possible routes: (1) The direct route might act through cognitive stimulation, social interaction, or physical activity. (2) The indirect route might have beneficial effects through avoidance of negative factors such as depression, disuse, and isolation.

During the last decades some of the aforementioned lifestyle factors, such as the positive effects of physical fitness on cognition and well-being have received increasing attention (Colcombe and Kramer, 2003; Heyn et al., 2004; Netz et al., 2005; see also Kramer and Erickson, 2007; Hillman et al., 2008 for a review). For example, Netz and colleagues (2005) found in a metaanalytic study that groups of participants engaged in physical exercise increased their well-being $(d=0.24)$ while controls did not show a significant difference in this respect $(d=0.09)$. The authors argued that as a consequence of the increased level of cardiovascular capacity and strength, functional capacity, selfefficacy, and anxiety levels were positively influenced. Colcombe and Kramer (2003) showed in another metaanalysis that fitness training had a positive effect on cognition. Their analysis revealed a robust, beneficial, and general effect of physical fitness on all obtained cognitive outcome measures. A more differentiated look at the data showed that executive control gained most from the interventions (net effect size $d=0.68$ ), followed by controlled processes $(d=0.32)$, spatial ability $(d=0.35)$, and processing speed $(d=0.22)$. In recent investigations, these results on the cognitive level received further support by demonstrations of trainingrelated changes in brain functioning and structure (e.g. Colcombe et al., 2004; Colcombe et al., 2006).

Taking together, the protective effect of aerobic exercise on well-being and cognition seems unequivocal. The scope of positive transfer to cognitive functions achieved by physical fitness interventions is truly remarkable. This point is further emphasized by the weak evidence for broad transfer effects coming from cognitive training (cf. Schaefer et al., 2006). The emerging questions now are twofold: (1) what are the underlying mechanisms that cause this major effect of physical fitness on cognition and (2) what is the relation between the gains originating from fitness-training as opposed to cognitive training? The former of these two questions has recently been addressed mainly by nonhuman animal studies. Main results of these studies are training-induced proliferation and survival of new cells in the dentate gyrus of the hippocampus (van Praag et al., 2005), angiogenesis (Kleim et al., 2002), and the upregulation of the neurotrophic factor BDNF (Ferris et al., 2007), which is crucial for synaptic long-term potentiation (LTP) as for neuronal growth and survival. Therefore it seems that physical exercise provides the brain with an increased level of functioning and plasticity.

What are the differences and what are the commonalities between the effects of physical training, on the one hand, and cognitive training, on the other? Promoting the neurogenic reserve hypothesis, Kempermann (2008) discussed that point by drawing on the example of hippocampal neurogenesis. Following his line of reasoning, the effects of physical activation are "setting the stage" on which experience-related activation can act. More specifically, this means that physical activity can lead to a transient, non-specific proliferation and division of precursor cells that are then recruited and consolidated through learning. Consequently, he proposes that, on the long term, it is not physical activity alone that increases cognitive functioning but also the presence of a cognitive challenge. This prediction is of great importance for psychological training research, both from conceptual and applied perspectives. The central question is whether the gains originating from both training strategies are mutually independent and therefore positively interact or whether they share 
common variance and therefore have little impact on each other. Clearly, studies combining both types of intervention are needed to address these questions.

\subsection{Conclusions}

In 1988, Baltes and Lindenberger concluded that the effects of cognitive training of elderly people did not spread beyond the boundaries of the task spaces that had been trained. After reviewing intervention studies that have been conducted since that time we cannot but conclude that this statement still possesses some validity. Though a wide range of tasks and intervention formats has been examined in the meantime, evidence for far positive transfer is almost entirely absent. Specifically, only one study reveals intervention-related gains in far transfer tasks that are moderate to large in size (Karbach and Kray, in press). The results of this study are even more remarkable because the amount of training given was comparably small. Consequently, the question arises what the distinguishing feature of this study is compared to all the other ones. Obviously, the trained task is unique in the ensemble of reviewed articles. A closer look at the work also targeting executive functioning (Basak et al., 2008; Bherer et al., 2005; Kramer et al, 1995) reveals that the findings, though not that strong, go in the same direction.

Why, then, is it the case that interventions aiming at enhancing cognitive control tend to produce the most promising results within the realm of cognitive interventions? It is tempting to speculate that older adults may have become used in exerting cognitive control to compensate for the widespread losses in sensation, perception, and cognition that come with normal aging. For example, it has been proposed that basic functions like speech perception (Schneider and Pichora-Fuller, 2000) and walking (Huxhold et al., 2006; Lindenberger et al., 2000; Lövdén et al., 2005; Schäfer et al., 2006) impose increasingly high demands on cognitive resources with advancing age, due to reduced signal quality and reduced automaticity. It can therefore be assumed that task integration and coordination skills are crucial for the success of control-based compensational strategies. From this standpoint, we conclude that the training of executive control skills might be particularly beneficial for aging individuals. Given that some of the more successful interventions consisted of a small number of sessions, the general mechanism of change through which improvements occurred may have been flexibility, rather than plasticity (see above). As we have pointed out elsewhere, the brain would be a frag- ile organ if it would react with broad changes to a few sessions of cognitive intervention in a psychological laboratory (Lövdén et al., 2008)

Finally, when evaluating transfer effects in multiple studies, a major problem comes with the categorization of the transfer effect itself. To date generalization is typically addressed by tasks referred to either one of two categories: near transfer and far transfer. In practice, this distinction has proven to be too crude and oftentimes equivocal because the positioning of tasks on the near-far transfer continuum appears rather arbitrary. To overcome this unsatisfactory situation, target tasks and transfer tasks need to be projected into a common space or metric that specifies their relation in a more rigorous manner. Thus, we would like to end this review by suggesting a taxonomy of transfer distance that may serve this purpose.

\section{A taxonomy of transfer distance}

At a general level, the notion of transfer comprises two dimensions: First, it underscores the importance of the physical, the functional, and the social context of behavior (Barnett and Ceci, 2002). Second, it serves to describe both the similarity in the nature of two tasks and the similarity in the processes that are operative. Especially the second dimension is challenging and therefore provoked a vivid debate in general and differential psychology for about one century (cf. Cronbach, 1957). In the domain of cognitive skills and abilities, for example, attempts have been undertaken to specify theories of transfer and to quantify transfer distance through taxonomies. The common-elements theory by Edward Thorndike (1906) provided a starting point for many of these attempts. Thorndike concluded that transfer can be expected only if tasks involve common "elements", which are typically of the kind of stimulus-response associations. Thorndike based that assumption on the finding of poor transfer between tasks that require similar operations like estimating the areas of triangles after having practiced estimating areas of rectangles (Thorndike and Woodworth, 1901). Using the claim of common elements as the basis to determine transfer distance, however, entails the need to identify these elements. Sometimes, task analysis may indeed allow the identification of common elements and motivate specific predictions about the extent and pattern of transfer to a new task (e.g., Anderson, 1987). Despite its appeal, however, the commonelements approach must fail whenever it is not known 
whether two tasks share obvious common elements or not. Under these circumstances, one must predict that transfer is either impossible - if no common elements are present - or unpredictable - if elements are present but their identities are unknown. Moreover, making differential predictions about the amount of transfer would require justifiable ways of counting and weighing the number of common elements. Ultimately, the computation of transfer distance on the basis of common elements may require no less than a comprehensive theory of the cognitive architecture of the human mind. Though attempts to predict transfer on the basis of such theories have been made (Kieras and Bovair, 1986; Singley and Anderson, 1986), it is fair to say that they have been limited to instruction in content domains of rather limited scope, such as the acquisition of algebra skills (Anderson, 1987).

A related approach is to use cognitive theories to specify mechanisms or component processes that are common to performance on different tasks. Obviously, this approach is constrained by the scope and accuracy of the cognitive theories representing the tasks in question. For broad concepts such as working memory the predictions following from this approach are too general to allow the definition of transfer distance unless further specifications about mechanisms and components are being made. That again requires a theory, strong enough, to arrive at the definition of common elements. For example, the n-back task (e.g., Cohen et al., 1997) and the operation span task (Turner and Engle, 1989) are both commonly used to measure working memory performance. The two tasks both involve the requirement to inhibit no longer relevant information. However, this shared task characteristic is not necessarily of help in predicting the extent of transfer between the two tasks. It may provide one possible dimension for explaining transfer if it is present, but it does not provide a firm ground for defining transfer distance, either in absolute terms or in relation to other tasks.

Given the current state of knowledge, attempts to determine transfer distance based on task analysis or cognitive process models may be successful in defining and predicting nearest transfer (Singley and Anderson, 1986). On this basis, the transfer from operation span to reading span would probably qualify as nearest transfer because both tasks share the primary demand to memorize lists of words. They differ only in the concurrent secondary requirement to verify either equations or sentences. Determining and comparing larger transfer distances, however, quickly becomes rather difficult.

A different, more descriptive approach to define transfer distance draws on the structure of individual differences in cognitive abilities. In this field of research, over 100 years of factor-analytic studies have converged on a hierarchical model of human intelligence. Carroll (1993) comprehensively summarized this literature in a three-stratum model (Fig. 2), containing 69 narrow abilities, eight broad abilities, and a factor of general intelligence at the top. Even though a structure capturing between-person differences is not necessarily informative about the structure of withinperson changes (Molenaar, 2004), one may still use it as an initial approximation to define different classes of transfer distance. Thus, different transfer extensions can be distinguished: (a) between tasks from the same narrow ability; (b) between tasks from different narrow, but the same broad ability; (c) between tasks from different broad abilities. Regarding the level of generality, transfer would then be located at the (a) narrow ability, (b) broad ability, or (c) general ability stratum. For example, transfer from Surface Development to Paper Folding could be defined as nearest transfer within the narrow factor of visualization. Transfer from Surface Development to the Embedded Figures test would qualify as near transfer within the broad factor of visual perception. Finally, observing transfer effects from Surface Development to Ideational Fluency would be interpreted as far transfer at the level of the general factor of intelligence.

Positive transfer of training from one task to another provides initial evidence that a given intervention has affected cognition in more or less general ways. This observation holds regardless of the transfer being classified as within a narrow ability, within a broad ability, or across broad abilities. However, in strict keeping with the three-stratum theory, we state that demonstrating transfer at the level of observed variables does not provide a sufficient basis for claiming that the intervention has altered the cognitive system at the level of cognitive abilities. To warrant this claim, positive transfer needs to be present at the level of latent factors representing the abilities in question. Typically, each of these factors is indexed by sets of non-overlapping tasks (usually no less than three). If transfer is restricted to single tasks, task-specific effects are difficult to exclude as alternative interpretations, even if existing theories do not point to obvious overlaps in task demands or applicable strategies. Just as abilities in factor-analytic research on the structure of intelligence are construed as the common variance of several tasks used to operationalize the ability, transfer at the level of abilities needs to be construed as an effect on the common variance of several transfer tasks. In the case of 


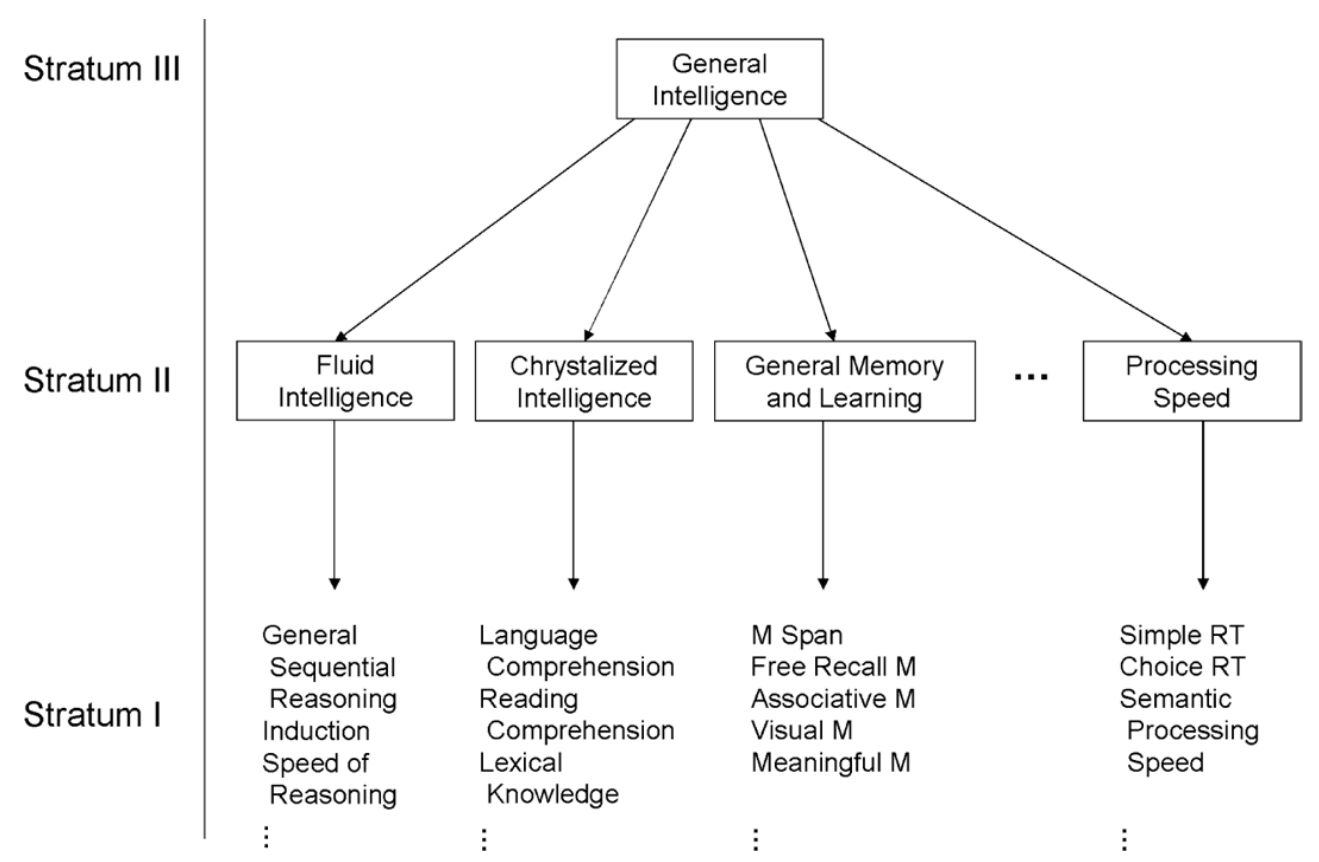

Fig. 2. The structure of abilities (adapted from Carroll, 1993; p. 626).

cognitive intervention studies the targeted transfer ability must be measured by several tasks. The common variance of these tasks can then be extracted applying appropriate methods such as confirmatory factor models, which allow for the investigation of training effects at the level of latent factors (McArdle and Nesselroade, 1994). If transfer can be shown at this latent level of cognitive abilities, then task-specific explanations become difficult to entertain, and a more solid basis for claims regarding the generality of intervention effects has been attained.

In light of these considerations, none of the studies reviewed above provides strong evidence that cognitive abilities have been affected by cognitive interventions. Few studies report transfer effects for tasks dissimilar enough from the trained tasks to suggest transfer at the level of broad abilities. In these studies, however, individual tasks have been used to represent the targeted transfer ability. Hence, one does not know for sure whether instances of positive transfer observed in these studies are restricted to the tasks in question, or generalize to cognitive abilities. To avoid these ambiguities and to delineate the generality of intervention effects with some degree of confidence, future studies need to sample a sufficiently large number of individuals per group and a sufficiently large number of representative tasks per factor. Following this strategy would allow researchers to model transfer at the level of cognitive abilities defined as constructs in latent space.

\section{Outlook}

A host of cognitive intervention studies with older adults document that the potential for experiencerelated performance improvements on cognitive tasks is maintained until very late in life. Instruction, selfguided practice, tutor-guided practice, and other forms of training all seem effective in improving the performance of children, younger adults, and older adults. However, our review shed some doubt on the generality and practical significance of these improvements, primarily because positive transfer of training is limited, and has not yet been documented at the level of latent abilities. Some studies show no evidence for transfer, other studies find narrow within-ability transfer, and only one study so far reported transfer effects that are moderate to large and that seem to reach beyond the narrow cognitive ability represented by the trained task. However, the comparative evaluation of all of these results is hindered by the absence of a common metric of transfer distance. We suggest that the structure of cognitive abilities, as summarized by Carroll (1993) in his three-stratum theory, may serve as a descriptive taxonomy of transfer distance in the foreseeable future.

At the same time, we expect that the prediction and evaluation of transfer distance on the basis of the structure of cognitive abilities will make contact with brainbased accounts of transfer distance that seem equal- 
ly promising (e.g., Dahlin et al., 2008). The two approaches may not always lead to the same predictions because tasks that are far away from each other in ability space may be closely related to each other in brain space. For instance, physical-exercise programs may improve cognitive abilities more effectively than many cognitive intervention programs because they directly enhance the functioning of the neural substrate in cognition-relevant cortical areas such as the prefrontal cortex and the hippocampus through angiogenesis, synaptogenesis, and possibly neurogenesis (Kempermann, 2008).

Hence, perspectives from developmental behavioral neuroscience may help to reconcile the divide between general and differential psychology, and contribute to a lifespan theory of cognitive plasticity (cf. Kinsbourne and Hicks, 1978).

\section{References}

Anderson, J. R. (1987). Skill acquisition: Compilation of weak method problem solutions. Psychol Rev, 94, 192-210.

Bäckman, L. \& Dixon, R. A. (1992). Psychological compensation A theoretical framework. Psychol Bull, 112(2), 259-283.

Bäckman, L., Nyberg, L., Lindenberger, U., Li, S. C. \& Farde, L. (2006). The correlative triad among aging, dopamine, and cognition: Current status and future prospects. Neurosci Biobehav Rev, 30(6), 791-807.

Baddely, A. (2007). Working memory, thought, and action. New York: Oxford University Press.

Ball, K. K., Berch, D. B., Helmers, K. F., Jobe, J. B., Leveck, M. D., Marsiske, M., et al. (2002). Effects of cognitive training interventions with older adults - A randomized controlled trial. JAMA, 288(18), 2271-2281.

Ball, K. K., Edwards, J. D. \& Ross, L. A. (2007). The impact of speed of processing training on cognitive and everyday functions. $J$ Gerontol B Psychol Sci Soc Sci, 62, 19-31.

Ball, K. K., Beard, B. L., Roenker, D. L., Miller, R. L. \& Griggs, D. S. (1988). Age and visual-search: Expending the useful field of view. J Opt Soc Am A Opt Image Sci Vis, 5(12), 2210-2219.

Baltes, P. B. \& Schaie, K. W. (1976). On the plasticity of intelligence in adulthood and old age: Where Horn and Donaldson fail. Am Psychol, 31, 720-725.

Baltes, P. B., Dittmann-Kohli, F. \& Kliegl, R. (1986). Reserve capacity of the elderly in aging-sensitive tests of fluid intelligence: replication and extension. Psychol Aging, 1(2), 172-177.

Baltes, P. B. \& Kliegl, R. (1992). Further testing of limits of cognitive plasticity - Negative age- differences in a mnemonic skill are robust. Dev Psychol, 28(1), 121-125.

Baltes, P. B. \& Lindenberger, U. (1988). On the range of cognitive plasticity in old-age as a function of experience - 15 years of intervention research. Behav Ther, 19(3), 283-300.
Baltes, P. B., Lindenberger, U. \& Staudinger, U. (2006). Lifespan theory in developmental psychology. In W. Damon \& R. M. Lerner (Eds.), Theoretical models of human development (6th ed., Vol. 1, pp. 569-664). New York: Wiley.

Baltes, P. B., Sowarka, D. \& Kliegl, R. (1989). Cognitive training research on fluid intelligence in old-age - What can older adults achieve by themselves. Psychol Aging, 4(2), 217-221.

Baltes, P. B. \& Willis, S. L. (1982). Plasticity and enhancement of intellectual functioning in old age: Penn state's adult development and enrichment project (ADEPT). In F. I. M. Craik \& E. E. Trehub (Eds.), Aging and cognitive processes (pp. 353-389). New York: Plenum Press.

Barnett, S. M. \& Ceci, S. J. (2002). When and where do we apply what we learn? A taxonomy for far transfer. Psychol Bull, 128(4), 612-637.

Bartzokis, G. (2004). Age-related myelin breakdown: a developmental model of cognitive decline and Alzheimer's disease. Neurobiol Aging, 25(1), 5-18.

Basak, C. B., Boot, W. R.; Voss, W. M.; Kramer, A. F. (2008). Can training in a real-time strategy video game attenuate cognitive decline in older adults? Psychol Aging, 23(4), 765-777.

Bherer, L., Kramer, A. F., Peterson, M. S., Colcombe, S., Erickson, K. $\&$ Becic, E. (2005). Training effects on dual-task performance: Are there age-related differences in plasticity of attentional control? Psychol Aging, 20(4), 695-709.

Boyke, J., Driemeyer, J., Gaser, C., Buechel, C. \& May, A. (2008). Training-induced brain structure changes in the elderly. $J$ Neurosci, 28(28), 7031-7035.

Brehmer, Y., Li, S. C., Muller, V., von Oertzen, T. \& Lindenberger, U. (2007). Memory plasticity across the life span: Uncovering children's latent potential. Dev Psychol, 43(2), 465-478.

Brehmer, Y., Li, S. C., Straube, B., Stoll, G., von Oertzen, T., Mueller, V., et al. (2008). Comparing memory skill maintenance across the life span: Preservation in adults, increase in children. Psychol Aging, 23(2), 227-238.

Briones, T. L., Klintsova, A. Y. \& Greenough, W. T. (2004). Stability of synaptic plasticity in the adult rat visual cortex induced by complex environment exposure. Brain Res, 1018(1), 130-135.

Buonomano, D. V. \& Merzenich, M. M. (1998). Cortical plasticity: From synapses to maps. Annu Rev Neurosci, 21, 149-186.

Cabeza, R., Anderson, N. D., Locantore, J. K. \& McIntosh, A. R. (2002). Aging gracefully: Compensatory brain activity in high-performing older adults. Neuroimage, 17(3), 1394-1402.

Cabeza, R., Daselaar, S. M., Dolcos, F., Prince, S. E., Budde, M. \& Nyberg, L. (2004). Task-independent and task-specific age effects on brain activity during working memory, visual attention and episodic retrieval. Cereb Cortex, 14(4), 364-375.

Caprio-Prevette, M. D. \& Fry, P. S. (1996). Memory enhancement program for community-based older adults: Development and evaluation. Exp Aging Res, 22(3), 281-303.

Carroll, J. B. (1993). Human cognitive abilities. Cambridge: University Press.

Caserta, R.J., Young, J. \& Janelle, C.M. (2007). Old dogs, new tricks: training in perceptual skills of senior tennis players. $J$ Sport Exerc Psychol, 29, 479-497.

Cavallini, E., Pagnin, A. \& Vecchi, T. (2003). Aging and everyday memory: the beneficial effect of memory training. Arch Gerontol Geriatr, 37(3), 241-257. 
Changeux, J. P. \& Danchin, A. (1976). Selective stabilization of developing synapses as a mechanism for specification of neuronal networks. Nature, 264(5588), 705-712.

Charlton, R. A., Barrick, T. R., McIntyre, D. J., Shen, Y., O’Sullivan, M., Howe, F. A., et al. (2006). White matter damage on diffusion tensor imaging correlates with age-related cognitive decline. Neurology, 66(2), 217-222.

Churchill, J. D., Galvez, R., Colcombe, S., Swain, R. A., Kramer, A. F., \& Greenough, W. T. (2002). Exercise, experience and the aging brain. Neurobiol Aging, 23, 941-955.

Cohen, J. D., Perlstein, W. M., Braver, T. S., Nystrom, L. E., Noll, D. C., Jonides, J., et al. (1997). Temporal dynamics of brain activation during a working memory task. Nature, 386(6625), 604-608.

Colcombe, S. J. \& Kramer, A. F. (2003). Fitness effects on the cognitive function of older adults: A meta-analytic study. Psychol Sci, 14(2), 125-130.

Colcombe, S. J., Erickson, K. I., Scalf, P. E., Kim, J. S., Prakash, R., McAuley, E., et al. (2006). Aerobic exercise training increases brain volume in aging humans. J Gerontol A Biol Sci Med Sci, 61(11), 1166-1170.

Colcombe, S. J., Kramer, A. F., Erickson, K. I., Scalf, P., McAuley, E., Cohen, N. J., et al. (2004). Cardiovascular fitness, cortical plasticity, and aging. Proc Natl Acad Sci USA, 101(9), 33163321.

Cooke, S. F. \& Bliss, T. V. P. (2006). Plasticity in the human central nervous system. Brain, 129, 1659-1673.

Cronbach, L. J. (1957). The two disciplines of scientific psychology. Am Psychol, 12, 671-684.

Dahlin, E., Stigsdotter Neely, A. S., Larsson, A., Bäckman, L. \& Nyberg, L. (2008). Transfer of learning after updating training mediated by the striatum. Science, 320(5882), 1510-1512.

Davis, S. W., Dennis, N. A., Daselaar, S. M., Fleck, M. S. \& Cabeza, R. (2008). Que PASA? The posterior-anterior shift in aging. Cereb Cortex, 18(5), 1201-1209.

Denney, N. W. \& Heidrich, S. M. (1990). Training effects on ravens progressive matrices in young, middle-aged, and elderly adults. Psychol Aging, 5(1), 144-145.

Derwinger, A., Neely, A. S., Persson, M., Hill, R. D. \& Bäckman, L. (2003). Remembering numbers in old age: Mnemonic training versus self-generated strategy training. Aging Neuropsychol C, 10(3), 202-214.

Dittmann-Kohli, F., Lachman M. E., Kliegl, R. \& Baltes, P. B. (1991). Effects of cognitive training and testing on intellectual efficacy beliefs in elderly adults. J Gerontol, 46(4), 162-164.

Draganski, B., Gaser, C., Busch, V., Schuierer, G., Bogdahn, U. \& May, A. (2004). Neuroplasticity: Changes in grey matter induced by training - Newly honed juggling skills show up as a transient feature on a brain-imaging scan. Nature, 427(6972), 311-312.

Draganski, B., Gaser, C., Kempermann, G., Kuhn, H. G., Winkler, J., Buchel, C., et al. (2006). Temporal and spatial dynamics of brain structure changes during extensive learning. J Neurosci, 26(23), 6314-6317.

Draganski, B., Moser, T., Lummel, N., Ganssbauer, S., Bogdahn, U., Haas, F., et al. (2006). Decrease of thalamic gray matter following limb amputation. Neuroimage, 31(3), 951-957.
Edwards, J. D., Ross, L. A., Wadley, V. G., Clay, O. J., Crowe, M., Roenker, D. L., et al. (2006). The useful field of view test: Normative data for older adults. Arch Clin Neuropsychol, 21(4), 275-286

Edwards, J. D., Vance, D. E., Wadley, V. G., Cissell, G. M., Roenker, D., \& Ball, K. K. (2005). Reliability and validity of useful field of view test scores as administered by personal computer. J Clin Exp Neuropsychol, 27(5), 529-543.

Edwards, J. D., Wadley, V. G., Myers, R. S., Roenker, D. L., Cissell, G. M., \& Ball, K. K. (2002). Transfer of a speed of processing intervention to near and far cognitive functions. Gerontology, 48(5), 329-340.

Edwards, J. D., Wadley, V. G., Vance, D. E., Wood, K., Roenker, D. L. \& Ball, K. K. (2005). The impact of speed of processing training on cognitive and everyday performance. Aging Ment Health, 9(3), 262-271.

Eriksson, P. S., Perfilieva, E., Bjork-Eriksson, T., Alborn, A. M., Nordborg, C., Peterson, D. A., et al. (1998). Neurogenesis in the adult human hippocampus. Nat Med, 4(11), 1313-1317.

Farkas, E. \& Luiten, P. G. M. (2001). Cerebral microvascular pathology in aging and Alzheimer's disease. Prog Neurobiol, 64(6), 575-611.

Ferris, L. T., Williams, J. S. \& Shen, C. L. (2007). The effect of acute exercise on serum brain-derived neurotrophic factor levels and cognitive function. Med Sci Sports Exerc, 39(4), 728-734.

Garrett, H. E. (1946). A developmental theory of intelligence. Am Psychol, 1, 372-378.

Gopher, D., Weil, M. \& Bareket, T. (1994). Transfer of skill from a computer game trainer to flight. Hum Factors, 36(3), 387-405.

Grady, C. L. (2001). The role of the frontal lobes in age-related changes in cognition. Brain Cogn, 47(1-2), 15-16.

Green, C. S. \& Bavelier, D. (2006). Effect of action video games on the spatial distribution of visuospatial attention. J Exp Psychol Hum Percept Perform, 32(6), 1465-1478.

Green, C. S. \& Bavelier, D. (2007). Action-video-game experience alters the spatial resolution of vision. Psychol Sci, 18(1), 8894.

Greenough, W. T., Black, J. E. \& Wallace, C. S. (1987). Experience and brain-development. Child Dev, 58(3), 539-559.

Greenwood, P. M. (2007). Functional plasticity in cognitive aging: Review and hypothesis. Neuropsychology, 21(6), 657-673.

Gutchess, A. H., Welsh, R. C., Hedden, T., Bangert, A., Minear, M., Liu, L. L., et al. (2005). Aging and the neural correlates of successful picture encoding: Frontal activations compensate for decreased medial-temporal activity. J Cogn Neurosci, 17(1), 84-96.

Hedden, T. \& Gabrieli, J. D. E. (2004). Insights into the ageing mind: A view from cognitive neuroscience. Nat Rev Neurosci, 5(2), 87-96.

Hensch, T. K. (2004). Critical period regulation. Annu Rev Neurosci, 27, 549-579.

Hensch, T. K. (2005). Critical period plasticity in local corticalcircuits. Nat Rev Neurosci, 6, 877-888.

Hertzog, C., F., K., Wilson, R. S. \& Lindenberger, U. (2009). Enrichment effects on adult cognitive development: Can the functional capacity of older adults be preserved and enhanced? Psychol Sci Pub Int. 
Heuninckx, S., Wenderoth, N., Debaere, F., Peeters, R. \& Swinnen, S P. (2005). Neural basis of aging: The penetration of cognition into action control. J Neurosci, 25(29), 6787-6796.

Heyn, P., Abreu, B. C. \& Ottenbacher, K. J. (2004). The effects of exercise training on elderly persons with cognitive impairment and dementia: A meta-analysis. Arch Phys Med Rehabil, 85(10), 1694-1704.

Hillman, C. H., Erickson, K. I. \& Kramer, A. F. (2008). Be smart, exercise your heart: exercise effects on brain and cognition. Nat Rev Neurosci, 9(1), 58-65.

Hof, P. R. \& Morrison, J. H. (2004). The aging brain: morphomolecular senescence of cortical circuits. Trends Neurosci, 27(10), 607-613.

Horn, J. L. \& Donaldson, G. (1976). On the myth of intellectual decline in adulthood. Am Psychol, 31, 701-719.

Huttenlocher, P. R. (1979). Synaptic density in human frontal-cortex - developmental-changes and effects of aging. Brain Res, 163(2), 195-205.

Huttenlocher, P. R. (2000). Synaptogenesis in human cerebral cortex and the concept of critical periods. In N. A. Fox, L. A. Leavitt \& J. G. Warhol (Eds.), The Role of Early Experience in Infant Development (pp. 15-28). St. Louis: Johnson \& Johnson Pediatric Institute.

Jacoby, L. L. (1991). A process dissociation framework - separating automatic from intentional uses of memory. J Mem Lang, 30(5), 513-541.

Jaeggi, S. M., Buschkuehl, M., Jonides, J. \& Perrig, W. J. (2008). Improving fluid intelligence with training on working memory. Proc Natl Acad Sci USA, 105(19), 6829-6833.

James, W. (1890). Principles of Psychology. New York: Henry Holt.

Jennings, J. M., Webster, L. M., Kleykamp, B. A. \& Dagenbach, D. (2005). Recollection training and transfer effects in older adults: Successful use of a repetition-lag procedure. Aging Neuropsychol C, 12(3), 278-298.

Karbach, J. \& Kray, J. (in press). How useful is executive control training? Age differences in near and far transfer of task switching training. Dev Sci.

Karni, A., Meyer, G., Jezzard, P., Adams, M. M., Turner, R. \& Ungerleider, L. G. (1995). Functional MRI evidence for adult moto cortex plasticity during motor skill learning. Nature, 377(6545), 155-158.

Kempermann, G. (2006). Adult neurogenesis. Stem cells and neuronal development in the adult brain. Oxford: Oxford University Press.

Kempermann, G. (2008). The neurogenic reserve hypothesis: what is adult hippocampal neurogenesis good for? Trends Neurosci, 31(4), 163-169.

Kempermann, G., Kuhn, H. G. \& Gage, F. H. (1997). More hippocampal neurons in adult mice living in an enriched environment. Nature, 386(6624), 493-495.

Kieras D. E. \& Bovair, S. (1986). The acquisition of procedures from text: A production-system analysis of transfer of training. $J$ Mem Lang, 25, 507-524.

Kinsbourne, M. \& Hicks, R. E. (1978). Functional cerebral space: A model for overflow, transfer and interference effects in human performance: A tutorial review. In J. Requin (Ed.), Attention and Performance VII (pp. 345-362). Hillsdale, New Jersey: Lawrence Erlbaum Associates.
Kleim, J. A., Cooper, N. R. \& VandenBerg, P. A. (2002). Exercise induces angiogenesis but does not alter movement representations within rat motor cortex. Brain Res, 934(1), 1-6.

Kliegl, R., Smith, J. \& Baltes, P. B. (1986). Testing the limits, expertise, and memory in adulthood and old age. In F. Klix \& H. Hagendorf (Eds.), Human memory and cognitive capabilities: Mechanisms and performances (pp. 395-407). Amsterdam: North Holland.

Kliegl, R., Smith, J. \& Baltes, P. B. (1989). Testing-the-limits and the study of adult age-differences in cognitive plasticity. Dev Psychol, 25(2), 247-256.

Kliegl, R., Smith, J. \& Baltes, P. B. (1990). On the locus and process of magnification of age-differences during mnemonic training. Dev Psychol, 26(6), 894-904.

Klingberg, T., Fernell, E., Olesen, P. J., Johnson, M., Gustafsson, P., Dahlstrom, K., et al. (2005). Computerized training of working memory in children with ADHD - A randomized, controlled trial. J Am Acad Child Adolesc Psychiatry, 44(2), 177-186.

Knudsen, E. I. (1998). Capacity in the adult owl auditory system expanded by juvenile experience. Science, 2, 1531-1533.

Kolb, B., Forgie, M., Gibb, R., Gorny, G. \& Rowntree, S. (1998). Age, experience and the changing brain. Neurosci Biobehav Rev, 22(2), 143-159.

Kramer, A. F. \& Erickson, K. I. (2007). Effects of physical activity on cognition, well-being, and brain: Human interventions. Alzheimers Dement, 3(2), S45-S51.

Kramer, A. F., Larish, J. F. \& Strayer, D. L. (1995). Training for attentional control in dual-task settings - a comparison of young and old adults. J Exp Psychol Appl, 1(1), 50-76.

Lenroot, R. K. \& Giedd, J. N. (2006). Brain development in children and adolescents: Insights from anatomical magnetic resonance imaging. Neurosci Biobehav Rev, 30(6), 718-729.

Lewin, K. (1946). Behavior and development as function of the total situation. In L. Carmichael (Ed.), Manual of Child Psychology. (pp. 791-844). New York: Wiley.

Li, S.-C., Schmiedek, F., Huxhold, O., Röcke, C., Smith, J. \& Lindenberger, U. (2008). Working memory plasticity in old age: practice gain, transfer, and maintenance. Psychol Aging, 23(4), 731-742.

Li, S. C. (2003). Biocultural orchestration of developmental plasticity across levels: The interplay of biology and culture in shaping the mind and behavior across the life span. Psychol Bull, 129(2), 171-194.

Li, S. C., Brehmer, Y., Shing, Y. L., Werkle-Bergner, M. \& Lindenberger, U. (2006). Neuromodulation of associative and organizational plasticity across the life span: Empirical evidence and neurocomputational modeling. Neurosci Biobehav Rev, 30(6), 775-790.

Li, S. C., Huxhold, O. \& Schmiedek, F. (2004). Aging and attenuated processing robustness - Evidence from cognitive and sensorimotor functioning. Gerontology, 50(1), 28-34.

Lindenberger, U. (2000). Anwendungsorientierte Interpretation zentraler Befunde kognitiver Forschung. In H.-W. Wahl \& C. Tesch-Römer (Eds.), Angewandte Gerontologie in Schlüsselbegriffen (pp. 83-89). Stuttgart: Kohlhammer.

Lindenberger, U. (2008). Was ist kognitives Altern? In U. M. Staudinger \& H. Häfner (Eds.), Was ist Alter(n)? (18). Berlin: Springer. 
Lindenberger, U., Li, S. C. \& Bäckman, L. (2006). Delineating brain-behavior mappings across the lifespan: Substantive and methodological advances in developmental neuroscience. Neurosci Biobehav Rev, 30(6), 713-717.

Lindenberger, U., Li, S. C., Lövdén, M. \& Schmiedek, F. (2007). The Center for Lifespan Psychology at the Max Planck Institute for Human Development: Overview of conceptual agenda and illustration of research activities. Int J Psychol, 42(4), 229242.

Lindenberger, U., Marsiske, M. \& Baltes, P. B. (2000). Memorizing while walking: Increase in dual-task costs from young adulthood to old age. Psychol Aging, 15(3), 417-436.

Lövdén, M. (2003). The episodic memory and inhibition accounts of age-related increases in false memories: A consistency check. J Mem Lang, 49(2), 268-283.

Lövdén, M. (in press). Decline-induced Plastic Changes of Brain and Behavior in Aging. In L. Bäckman \& L. Nyberg (Eds.), Memory, Aging, and the Brain. Oxford: Psychology Press.

Lövdén, M., Ghisletta, P. \& Lindenberger, U. (2005). Social participation attenuates decline in perceptual speed in old and very old age. Psychol Aging, 20(3), 423-434.

Lövdén, M., Bäckman, L., Lindenberger, U., Schäfer, S. \& Schmiedek, F. (2008). Does Plasticity Shape Cognitive Aging? The Framework of Adult Developmental Plasticity. Manuscript submitted for publication.

Madden, D. J., Whiting, W. L., Huettel, S. A., White, L. E., MacFall, J. R., \& Provenzale, J. M. (2004). Diffusion tensor imaging of adult age differences in cerebral white matter: relation to response time. Neuroimage, 21(3), 1174-1181.

Mahncke, H. W., Bronstone, A. \& Merzenich, M. M. (2006). Brain plasticity and functional losses in the aged: scientific bases for a novel intervention. Progr Brain Res, 157, 81-109.

Mahncke, H. W., Connor, B. B., Appelman, J., Ahsanuddin, O. N., Hardy, J. L., Wood, R. A., et al. (2006). Memory enhancement in healthy older adults using a brain plasticity-based training program: A randomized, controlled study. Proc Natl Acad Sci USA, 103(33), 12523-12528.

May, A., Hajak, G., Ganssbauer, S., Steffens, T., Langguth, B., Kleinjung, T., et al. (2007). Structural brain alterations following 5 days of intervention: Dynamic aspects of neuroplasticity. Cereb Cortex, 17(1), 205-210.

McArdle, J. J. (1994). Using multivariate data to structure developmental change. In S. H. Cohen \& H. W. Reese (Eds.), Life-span developmental psychology: Methodological contributions (pp. 223-267). Hillsdale, NJ: Larence Erlbaum Associates.

Mercado, E. (2008). Neural and cognitive plasticity: From maps to minds. Psychol Bull, 134(1), 109-137.

Milgram, N. W., Siwak-Tapp, C. T., Araujo, J. \& Head, E. (2006). Neuroprotective effects of cognitive enrichment. Ageing Res Rev, 5(3), 354-369.

Miller, E. K. \& Cohen, J. D. (2001). An integrative theory of prefrontal cortex function. Annu Rev Neurosci, 24, 167-202.

Mohs, R., Ashman, T., Jantzen, K., Albert, M., Brandt, J., Gordon, B., et al. (1998). A study of the efficacy of a comprehensive memory enhancement program in healthy elderly persons. Psychiatry Res, 77 (3), 183-195.

Molenaar, P. C. M. (2004). A manifesto on Psychology as idiographic science: Bringing the person back into scientific psychology, this time forever. Measurement, 2(4), 201-218.
Netz, Y., Wu, M. J., Becker, B. J. \& Tenenbaum, G. (2005). Physical activity and psychological well-being in advanced age: A meta-analysis of intervention studies. Psychol Aging, 20 (2), 272-284.

O’Sullivan, M., Jones, D. K., Summers, P. E., Morris, R. G., Williams, S. C. R. \& Markus, H. S. (2001). Evidence for cortical "disconnection" as a mechanism of age-related cognitive decline. Neurology, 57 (4), 632-638.

Olesen, P. J., Westerberg, H. \& Klingberg, T. (2004). Increased prefrontal and parietal activity after training of working memory. Nat Neurosci, 7(1), 75-79.

Ota, M., Obata, T., Akine, Y., Ito, H., Ikehira, H., Asada, T., et al. (2006). Age-related degeneration of corpus callosum measured with diffusion tensor imaging. Neuroimage, 31(4), 14451452.

Park, D. C. \& Reuter-Lorenz, P. A. (2009). The adaptive brain: Aging and neurocognitive scaffolding. Annu Rev Psychol, 60, 21.21-21.24

Pascual-Leone, A., Amedi, A., Fregni, F. \& Merabet, L. B. (2005). The plastic human brain cortex. Annu Rev Neurosci, 28, 377401.

Pascual-Leone, A., Dang, N., Cohen, L. G., Brasilneto, J. P., Cammarota, A., \& Hallett, M. (1995). Modulation of muscle responses evoked by transcranial magnetic stimulation during the acquisition of new fine motor-skills. J Neurophysiol, 74(3), 1037-1045

Persson, J. \& Reuter-Lorenz, P. A. (2008). Gaining Control Training Executive Function and Far Transfer of the Ability to Resolve Interference. Psychol Sci, 19(9), 881-888.

Raz, N., Lindenberger, U., Rodrigue, K. M., Kennedy, K. M., Head, D., Williamson, A., et al. (2005). Regional brain changes in aging healthy adults: General trends, individual differences and modifiers. Cereb Cortex, 15(11), 1676-1689.

Rizzo, M. \& Robin, D. A. (1996). Bilateral effects of unilateral visual cortex lesions in human. Brain, 119, 951-963.

Roenker, D. L., Cissell, G. M., Ball, K. K., Wadley, V. G. \& Edwards, J. D. (2003). Speed-of-processing and driving simulator training result in improved driving performance. Hum Factors, 45(2), 218-233

Rogers, R. L., Meyer, J. S. \& Mortel, K. F. (1990). After reaching retirement age physical-activity sustains cerebral perfusion and cognition. J Am Geriartr Soc, 38(2), 123-128.

Rönnlund, M. \& Nilsson, L. G. (2006). Adult life-span patterns in WAIS-R Block Design performance: Cross-sectional versus longitudinal age gradients and relations to demographic factors. Intelligence, 34(1), 63-78.

Rönnlund, M., Nyberg, L., Bäckman, L. \& Nilsson, L. G. (2005). Stability, growth, and decline in adult life span development of declarative memory: Cross-sectional and longitudinal data from a population-based study. Psychol Aging, 20(1), 3-18.

Salat, D. H., Tuch, D. S., Hevelone, N. D., Fischl, B., Corkin, S., Rosas, H. D., et al. (2004, Aug 19-20). Age-related changes in prefrontal white IF matter measured by diffusion tensor imaging. Paper presented at the Workshop on White Matter in the Cognitive Neurosciences, New York, NY.

Schäfer, S., Huxhold, O. \& Lindenberger, U. (2006). Healthy mind in healthy body? A review of sensorimotor-cognitive interdependencies in old age. Eur Rev Aging Phys A, 3, 45-54. 
Schaie, K. W. (1996). Intellectual development in adulthood: The Seattle longitudinal Study. New York: Cambridge University Press.

Schneider, B. A. \& Pichora-Fuller, M. K. (2000). Implications of perceptual deterioration for cognitive aging research. In F. I. M. Craik \& T. A. Salthouse (Eds.), Handbook of aging and cognition (2 ed., pp. 155-220). Mahwah, NJ: Erlbaum.

Schooler, C. \& Mulatu, M. S. (2001). The reciprocal effects of leisure time activities and intellectual functioning in older people: A longitudinal analysis. Psychol Aging, 16(3), 466-482.

Singer, W. (1995). Development and plasticity of cortical processing architectures. Science, 270, 758-764.

Singer, T., Verhaeghen, P., Ghisletta, P., Lindenberger, U. \& Baltes, P. B. (2003). The fate of cognition in very old age: Sixyear longitudinal findings in the Berlin Aging Study (BASE). Psychol Aging, 18(2), 318-331.

Singley, M. K. \& Anderson, J. R. (1986). A keystroke analysis of learning and transfer in text editing. Bull Psychon Soc, 24(5), 331-331.

Sowell, E. R., Thompson, P. M. \& Toga, A. W. (2004). Mapping changes in the human cortex throughout the span of life. Neuroscientist, 10(4), 372-392.

Stern, Y. (2002). What is cognitive reserve? Theory and research application of the reserve concept. J Int Neuropsychol Soc, $8(3), 448-460$.

Stigsdotter Neely, A. S. \& Bäckman, L. (1993). Long-term maintainance of gains from memory training in older adults - 2 3-1/2- year follow-up-studies. J Gerontol, 48(5), P233-P237.

Stigsdotter Neely, A. S. \& Bäckman, L. (1995). Effects of multifactorial memory training in old-age - generalizability across tasks and individuals. J Gerontol B Psychol Sci Soc Sci, 50(3), P134-P140.

Stigsdotter Neely, A. S. \& Bäckman, L. (1993). Maintainance of gains following multifactorial and unifactorial memory training in late adulthood. Educ Gerontol, 19(2), 105-117.

Sullivan, E. V. \& Pfefferbaum, A. (2006). Diffusion tensor imaging and aging. Neurosci Biobehav Rev, 30(6), 749-761.

Thorndike, E. L. (1906). Principles of teaching. New York: Seiler.

Thorndike, E. L. \& Woodworth, R. S. (1901). The influence of improvement in one mental function upon the efficiency of other functions. (I). Psychol Rev, 8, 247-261.

Tsujimoto, S. (2008). The prefrontal cortex: Functional neural development during early childhood. Neuroscientist, 14(4), 345358.
Turner, M. L. \& Engle, R. W. (1989). Is working memory capacity task dependent. J Mem Lang, 28(2), 127-154.

van Praag, H., Kempermann, G. \& Gage, F. H. (2000). Neural consequences of environmental enrichment. Nat Rev Neurosci, 1(3), 191-198.

van Praag, H., Shubert, T., Zhao, C. M. \& Gage, F. H. (2005). Exercise enhances learning and hippocampal neurogenesis in aged mice. J Neurosci, 25(38), 8680-8685.

Vance, D., Dawson, J., Wadley, V., Edwards, J., Roenker, D., Rizzo, M., et al. (2007). The accelerate study: The longitudinal effect of speed of processing training on cognitive performance of older adults. Rehabil Psychol, 52(1), 89-96.

Verhaeghen, P. \& Marcoen, A. (1996). On the mechanisms of plasticity in young and older adults after instruction in the method of loci: Evidence for an amplification model. Psychol Aging, 11(1), 164-178.

Verhaeghen, P., Marcoen, A. \& Goossens, L. (1992). Improving memory performance in the aged through mnemonic training - A meta-analytic study. Psychol Aging, 7(2), 242-251.

Wadley, V. G., Benz, R. L., Ball, K. K., Roenker, D. L., Edwards, J. A., \& Vance, D. E. (2003, Nov 21-25). Development and evaluation of home-based speed-of-processing training for older adults. Paper presented at the 56th Annual Meeting of the Gerontological-Society-of-America, San Diego, CA.

Willis, S. L., Tennstedt, S. L., Marsiske, M., Ball, K., Elias, J., Koepke, K. M., et al. (2006). Long-term effects of cognitive training on everyday functional outcomes in older adults. JAMA, 296(23), 2805-2814.

Wood, L. E. \& Pratt, J. D. (1987). Pegword mnemonic as an aid to memory in the elderly - A comparison of 4 age-groups. Educ Gerontol, 13(4), 325-339.

Wozniak, J. R. \& Lim, K. O. (2006). Advances in white matter imaging: A review of in vivo magnetic resonance methodologies and their applicability to the study of development and aging. Neurosci Biobehav Rev, 30(6), 762-774.

Yesavage, J. A. (1983a). Imagery pretraining and memory training in the elderly. Gerontology, 29(4), 271-275.

Yesavage, J. A. (1983b). Relaxation and memory training in the elderly. Gerontologist, 23, 94-94.

Yesavage, J. A., Rose, T. L. \& Bower, G. H. (1983). Interactive Imagery and Affective Judgments Improve Face-Name Learning in the Elderly. J Gerontol, 38(2), 197-203. 